Prepared for the U.S. Department of Energy

under Contract DE-AC05-76RL01830

\title{
He Transport and Fate of Tempered Martensitic Steels: Summary of Recent TEM Observations
}
DJ Edwards
RJ Kurtz
GR Odette
T Yamamoto

February 2010

Pacific Northwest

NATIONAL LABORATORY

Proudly Operated by Battelle Since 1965 



\title{
DISCLAIMER
}

This report was prepared as an account of work sponsored by an agency of the United States Government. Neither the United States Government nor any agency thereof, nor Battelle Memorial Institute, nor any of their employees, makes any warranty, express or implied, or assumes any legal liability or responsibility for the accuracy, completeness, or usefulness of any information, apparatus, product, or process disclosed, or represents that its use would not infringe privately owned rights. Reference herein to any specific commercial product, process, or service by trade name, trademark, manufacturer, or otherwise does not necessarily constitute or imply its endorsement, recommendation, or favoring by the United States Government or any agency thereof, or Battelle Memorial Institute. The views and opinions of authors expressed herein do not necessarily state or reflect those of the United States Government or any agency thereof.

\author{
PACIFIC NORTHWEST NATIONAL LABORATORY \\ operated by \\ BATTELLE \\ for the \\ UNITED STATES DEPARTMENT OF ENERGY \\ under Contract DE-AC05-76RL01830
}

Printed in the United States of America
Available to DOE and DOE contractors from the Office of Scientific and Technical Information,
P.O. Box 62, Oak Ridge, TN 37831-0062;
ph: (865) 576-8401
fax: $(865)$ 576-5728
email: reports@adonis.osti.gov

\footnotetext{
Available to the public from the National Technical Information Service, U.S. Department of Commerce, 5285 Port Royal Rd., Springfield, VA 22161 ph: (800) 553-6847 fax: (703) 605-6900 email: orders@ntis.fedworld.gov online ordering: http://www.ntis.gov/ordering.htm
}

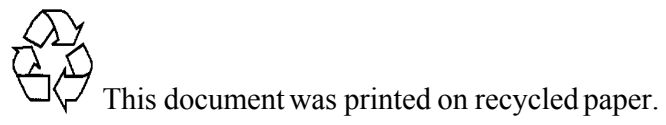




\title{
He Transport and Fate of Tempered Martensitic Steels: Summary of Recent TEM Observations
}

\author{
DJ Edwards \\ RJ Kurtz \\ GR Odette \\ T Yamamoto
}

February 2010

Prepared for the U.S. Department of Energy under Contract DE-AC05-76RL01830 
He Transport and Fate of Tempered Martensitic Steels: Summary of Recent TEM Observations D. J. Edwards, R. J. Kurtz (Pacific Northwest National Laboratory, Richland, WA 99336, USA), G. R. Odette and T. Yamamoto (University of California, Santa Barbara, CA 93106-5070, USA)

\section{OBJECTIVE}

The work discusses the recent investigation of in-situ He-implanted tempered martensitic steels irradiated in HFIR using transmission electron microscopy.

\section{SUMMARY}

As an extension of prior work [1-4], we summarize recent observations made on a He-implanted tempered martensitic steel (TMS), F82H mod 3, irradiated in the HFIR, in both as-tempered (AT) and cold-worked $(\mathrm{CW})$ conditions. A novel implantation technique was used to uniformly inject He into 3-mm diameter TEM discs to depths ranging from $\approx 5-8 \mu \mathrm{m}$. The He is generated by two-step transmutation reactions in Ni contained in a NiAl coating layer adjacent to paired $3 \mathrm{~mm}$ TEM discs. NiAl layers from 1 to $4 \mu \mathrm{m}$ thick produced He/dpa ratios between 5 and $40 \mathrm{appm} / \mathrm{dpa}$. The irradiations were at temperatures of 300,400 and $500^{\circ} \mathrm{C}$ from 3.9 to $9 \mathrm{dpa}$ and 90 to $380 \mathrm{appm}$ He. Electron transparent samples were prepared by a cross-sectional thinning technique that allowed investigating microstructural evolution over a range of implantation depths. Irradiation of the AT alloy to $9 \mathrm{dpa}$ at $500^{\circ} \mathrm{C}$ and $380 \mathrm{appm}$ He resulted in relatively large, faceted cavities, that are likely voids, along with a much higher density of smaller $\mathrm{He}$ bubbles. The cavities were most often aligned in pearl necklace like strings, presumably due to their formation on pre-existing dislocations. A finer distribution of cavities was also present on precipitate interfaces, lath and grain boundaries. Nine dpa irradiations that produced 190 appm He resulted in a somewhat more random distribution and lower density of smaller matrix cavities; but lower He levels had a less noticeable effect on bubbles in the lath and precipitate boundaries. Corresponding irradiations of the $\mathrm{CW}$ F82H produced a larger number of smaller cavities. Irradiation of the AT alloy to $3.9 \mathrm{dpa}$ and 90 $\mathrm{ppm} \mathrm{He}$ at $400^{\circ} \mathrm{C}$ produced a similar cavity population to that observed at $500^{\circ} \mathrm{C}$ at $190 \mathrm{appm} \mathrm{He}$, while the corresponding cavities at $500^{\circ} \mathrm{C}$ are slightly larger and more numerous at 380 appm He. The cavity strings were less obvious for the $400^{\circ} \mathrm{C}$ irradiations, and the bubble distribution appeared to be more random. No cavities were observed in the case of the $300^{\circ} \mathrm{C}$ irradiations. Overall the cavity number densities compare favorably with those previously reported [4], but details, including size distributions, are still under investigation. Dislocation structures were complex and varied greatly as a function of irradiation dose and temperature, and will be more thoroughly characterized in the next phase of the work.

\section{PROGRESS AND STATUS}

\section{Introduction}

Understanding the effects of He accumulation during neutron irradiation is a key challenge to developing materials for fusion energy. For example, He bubbles in the grain interiors and He on grain boundaries enhance void swelling and fast fracture, respectively. The key to understanding the effects of $\mathrm{He}$, is a corresponding understanding and models of its transport and fate, including interactions with displacement damage, and as mediated by both metallurgical (starting composition, dislocation, grain and precipitate structures) and irradiation (dpa and dpa rate, He/dpa ratio, temperature) variables.

A novel in situ implantation technique was used to uniformly inject He into 3-mm diameter TEM discs to a depth of about 5-8 $\mu \mathrm{m}$. The He is generated by two-step transmutation reactions in Ni contained in a NiAl coating layer adjacent to paired $3 \mathrm{~mm}$ TEM discs. The He/dpa ratios are determined by the thickness of the Ni-Al layer. The in situ injection technique has been applied to a large matrix of structural steels and model alloys in the JP26-29 experiments in HFIR. Details of this coating process and irradiations have been described in detail in earlier publications [2-5]. Here we focus on in situ implantation studies of a TMS alloy F82H mod 3 in both AT and CW conditions, at various temperatures, dpa and He levels. 


\section{Experimental Procedure}

The $\mathrm{F} 82 \mathrm{H}$ alloy irradiated in this study is a high-Ta variant called $\mathrm{F} 82 \mathrm{H}-\bmod 3$ [4] produced by modifying the F82H-IEA alloy, with $7.5 \% \mathrm{Cr}, 2 \% \mathrm{~W}, 0.2 \% \mathrm{~V}, 0.1 \% \mathrm{C}, 0.1 \% \mathrm{Si}, 0.02 \% \mathrm{Ta}$ and $60 \mathrm{ppm} \mathrm{N}$. The $\mathrm{N}$ and Ti were reduced to $14 \mathrm{ppm}$ and $0.001 \%$, respectively, in mod3 and the Ta was increased to $0.1 \%$. The AT condition involved austenitization at $1040^{\circ} \mathrm{C}$ for 30 minutes followed by normalization (air-cooling) and tempering at $750^{\circ} \mathrm{C}$ for 1.5 hours. The $\mathrm{CW}$ condition was achieved by cold rolling AT coupons to a $20 \%$ thickness reduction. A large number of 3-mm TEM discs were punched and coated with a thin Ni-Al intermetallic layer by electron beam deposition at the UCSB Materials Processing Laboratory. Nominal coating thicknesses were 1,2 and $4 \mu \mathrm{m}$, which yields He/dpa ratios of 5,20 and 40 in the HFIR PTP position at $9 \mathrm{dpa}$. The discs in this study were irradiated in HFIR JP26 experiment at $300,400^{\circ} \mathrm{C}$ to 3.9 dpa and at $500^{\circ} \mathrm{C}$ to $9 \mathrm{dpa}$. A summary of the irradiation matrix is shown in Table 1.

Table 1. Irradiation Matrix for F82H mod3 for both AT and CW conditions. The shaded conditions have not been examined.

\begin{tabular}{|c|c|c|c|}
\hline $\begin{array}{c}\text { Nominal } \\
\text { Ni-Al Thickness }\end{array}$ & $300^{\circ} \mathrm{C}, 3.9 \mathrm{dpa}$ & $400^{\circ} \mathrm{C}, 3.9 \mathrm{dpa}$ & $500^{\circ} \mathrm{C}, 9 \mathrm{dpa}$ \\
\cline { 2 - 4 } & $\begin{array}{c}\text { Total } \mathrm{He} \\
(\mathrm{appm})\end{array}$ & $\begin{array}{c}\text { Total He } \\
(\text { appm) }\end{array}$ & $\begin{array}{c}\text { Total He } \\
\text { (appm) }\end{array}$ \\
\hline 0 & 0 & 0 & 0 \\
\hline 1 & 20 & 20 & 95 \\
\hline 2 & 45 & 45 & 190 \\
\hline 4 & 90 & 90 & 380 \\
\hline
\end{tabular}

Cross-sectional TEM specimens were prepared by mounting the implanted disc between two pieces of a split Mo rod. The rod was then sectioned into thin wafers, composed of a sandwich of Mo-F82H-Mo. The wafers were then mounted on a stainless steel washer for support, dimpled and ion milled to electron transparency in a Gatan Precision Ion Polishing Instrument at $5 \mathrm{keV}$ with $6^{\circ}$ tilt in the dual beam mode. The milling started in the middle of the $\mathrm{F} 82 \mathrm{H}$ and gradually expanded until perforation was achieved at the vicinity of the Ni-Al interface. This process yielded a continuous range of thinned material over distances that can be referenced to the Ni-Al layer. To remove as much of the ion damage as possible, a final 20 minute ion polish was carried out at $1.9 \mathrm{keV}$ and $4^{\circ}$ tilt.

The cross-sectional TEM specimens were characterized using a JEOL 2010F at PNNL. The instrument was operated at $200 \mathrm{keV}$ and all images were recorded digitally using a Gatan ORIUS CCD camera. Various techniques were used to image the cavity and dislocation microstructures. Through focal sequence images were used to study the bubbles and void microstructures in the lath interiors and at interfaces. Images taken both within and outside the uniform $\mathrm{He}$ deposition region were carefully examined in order to better understand surface and Ar ion milling artifacts. Dislocations were imaged using $\mathbf{g}(011)$ reflections, and thickness estimates were obtained using convergent beam diffraction. 


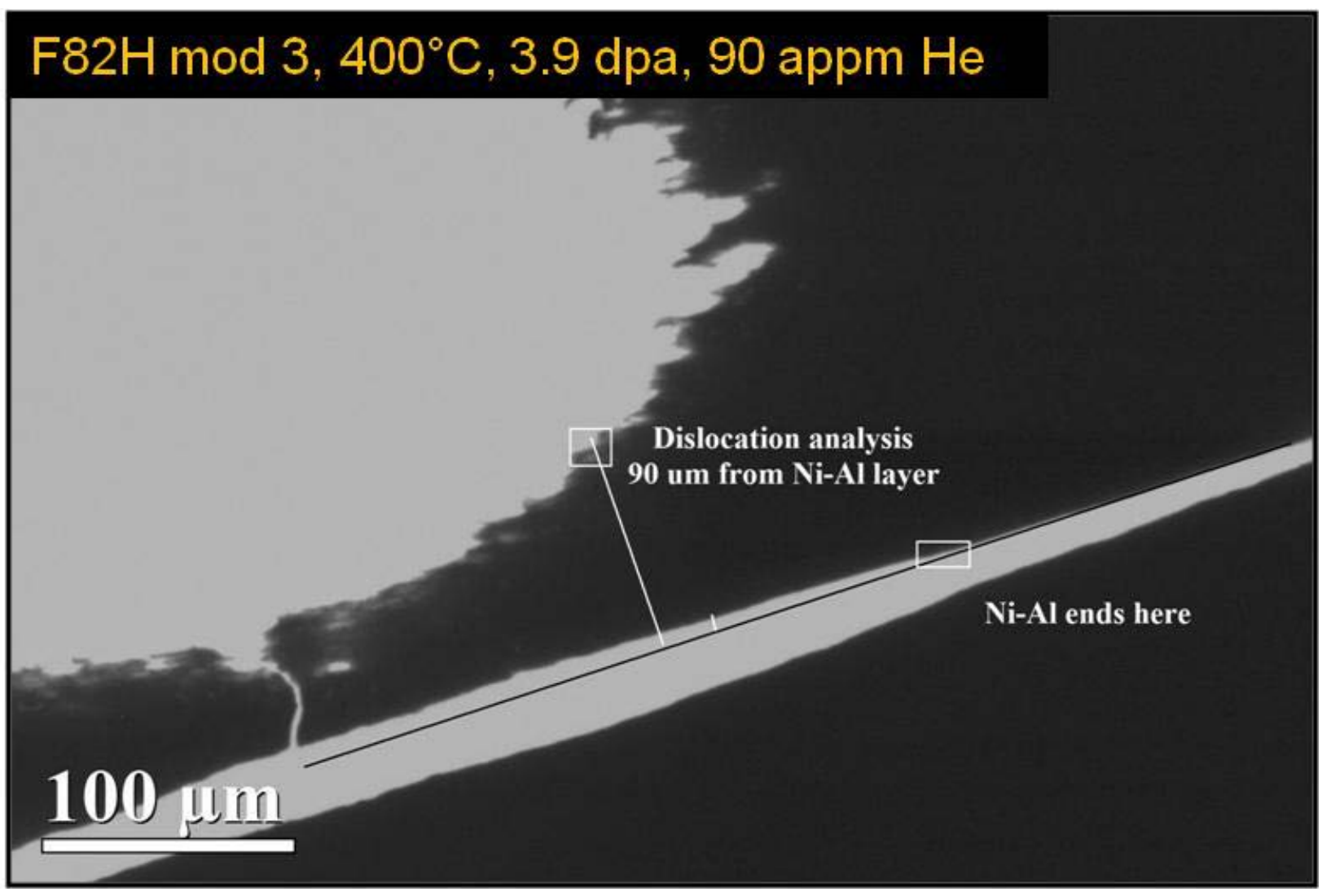

Figure 1. A low magnification image of a cross-section sample after final ion polishing.

A low magnification example of a thinned sample after final ion polishing is shown in Figure 1, highlighting the location of the Ni-Al interface. Individual samples thinned a bit differently, but overall it was possible to reliably characterize the microstructure both within and outside the uniform He deposition layer.

\section{Results and Discussion}

The average size and number density of the cavities for the two alloy and various irradiation conditions are summarized in Table 2. In this report we use the term cavities in a generic sense to refer to both Hefilled cavities and faceted voids. By definition voids are larger, and in this case faced features, while bubbles are smaller and below the critical size and He content to growing voids. The presence of bubbles and void is often manifested in a bimodal cavity size distribution, although the precise transition between the two forms at intermediate sizes may be difficult to distinguish We first describe results for irradiations at $500^{\circ} \mathrm{C}$ to $9 \mathrm{dpa}$. Examples of strings of bubbles and voids found in two regions are shown in Figure 2 for the AT alloy containing $380 \mathrm{appm} \mathrm{He}$. These results suggest a strong cavity association with dislocations. However, tilt experiments indicated that this association did not persist since dislocations were no longer present in the vicinity of the cavity stringers. Presumably, the He bubbles nucleated on pre-existing dislocations, but under further irradiation the dislocations climbed away, perhaps before the formation of voids. Note that the observation of strings of cavities was reported in our earlier work; however, at the time it wasn't clear if the original dislocations were still present. The comparison in Figure 3 shows a distribution of smaller, less numerous and more randomly distributed cavities in the AT alloy containing a lower concentration of $190 \mathrm{appm} \mathrm{He}$. Cold working increases the density and decreases the size of the visible cavities, and appears to suppress the formation of larger voids. 


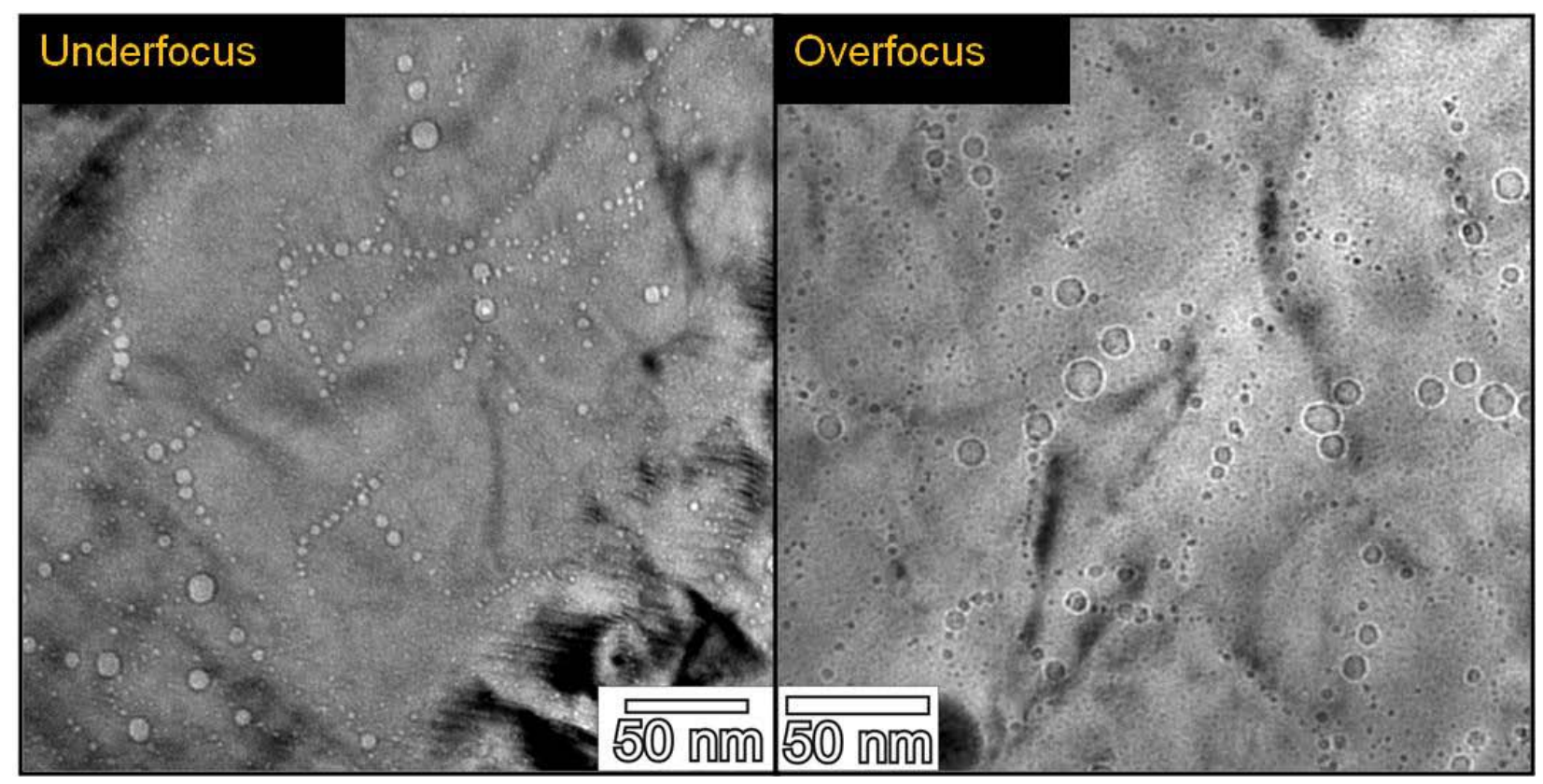

Figure 2. Examples of the bubbles and voids formed during irradiation at $500^{\circ} \mathrm{C}$ in the AT F82H mod3. The images were taken in different regions, one in the underfocussed $(-1280 \mathrm{~nm})$ condition and the other in the overfocussed $(+1280 \mathrm{~nm})$ condition. Most cavities appear to have formed on pre-existing dislocations that are no longer present, perhaps due to climb during irradiation.

As shown in Figure 3, bubbles were also observed on lath boundaries and carbide interfaces in both the AT and the CW conditions at both 190 and 380 appm He. Virtually all lath boundaries appeared to have a high density of small bubbles, while the corresponding bubble association with carbides was more sporadic. The numbers and sizes of the interface bubbles have not yet been quantified.

In the case of irradiation at $400^{\circ} \mathrm{C}$ to $3.9 \mathrm{dpa}$ and $90 \mathrm{appm} \mathrm{He}$, cavities were clearly observed only in the AT condition. Smaller features that may be bubbles were seen in both the AT and CW condition, but they could not reliably be distinguished from ion polishing and surface artifacts. Examples of the cavities in the AT alloy are shown in Figure 4 in regions with different thickness. The cavity distribution appears to be more random in this case, with less obvious association with either dislocations or interfaces. These results are not surprising, since lower temperature alone would be expected to result in smaller more homogeneously nucleated bubbles. Thus these observations are consistent with a population of subvisible bubbles that require higher dpa and He levels to grow to the size range where the can be clearly observed in TEM. TEM did not identify any cavities that could be distinguished with confidence from the surface and ion polishing artifacts for the $300^{\circ} \mathrm{C}$ irradiations. Comparisons of cavity size distributions for the various irradiation and alloy conditions are shown in Figure 5. 


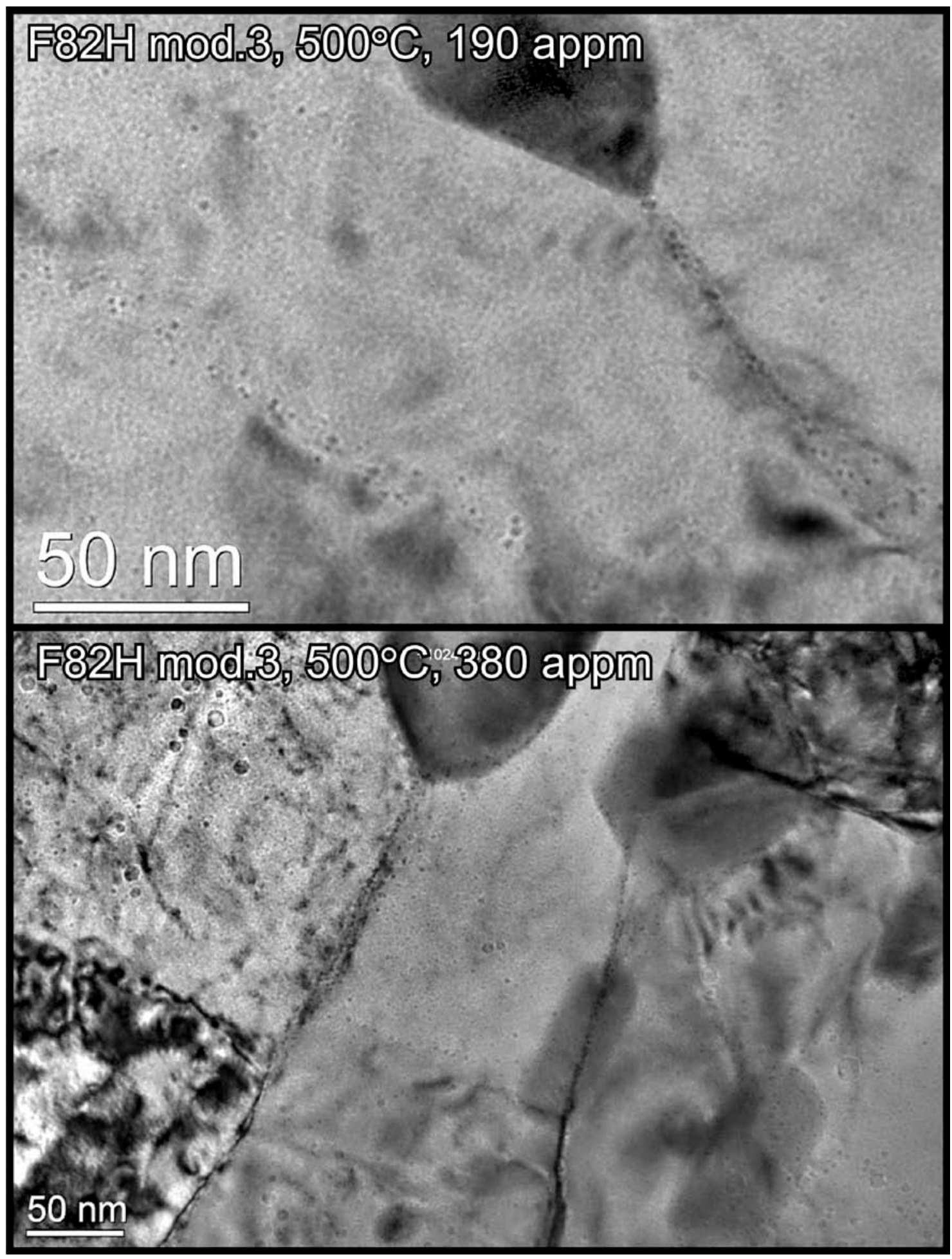

Figure 3. TEM bright field images showing He bubbles on lath boundaries and carbide interfaces in the AT $\mathrm{F} 82 \mathrm{H}$ mod3 alloy irradiated at $500^{\circ} \mathrm{C}$ to the indicated He levels. Small He bubbles decorate virtually every lath boundary, whereas bubbles are somewhat more sporadically distributed on the carbide interfaces. Both images were taken in an overfocussed condition. 


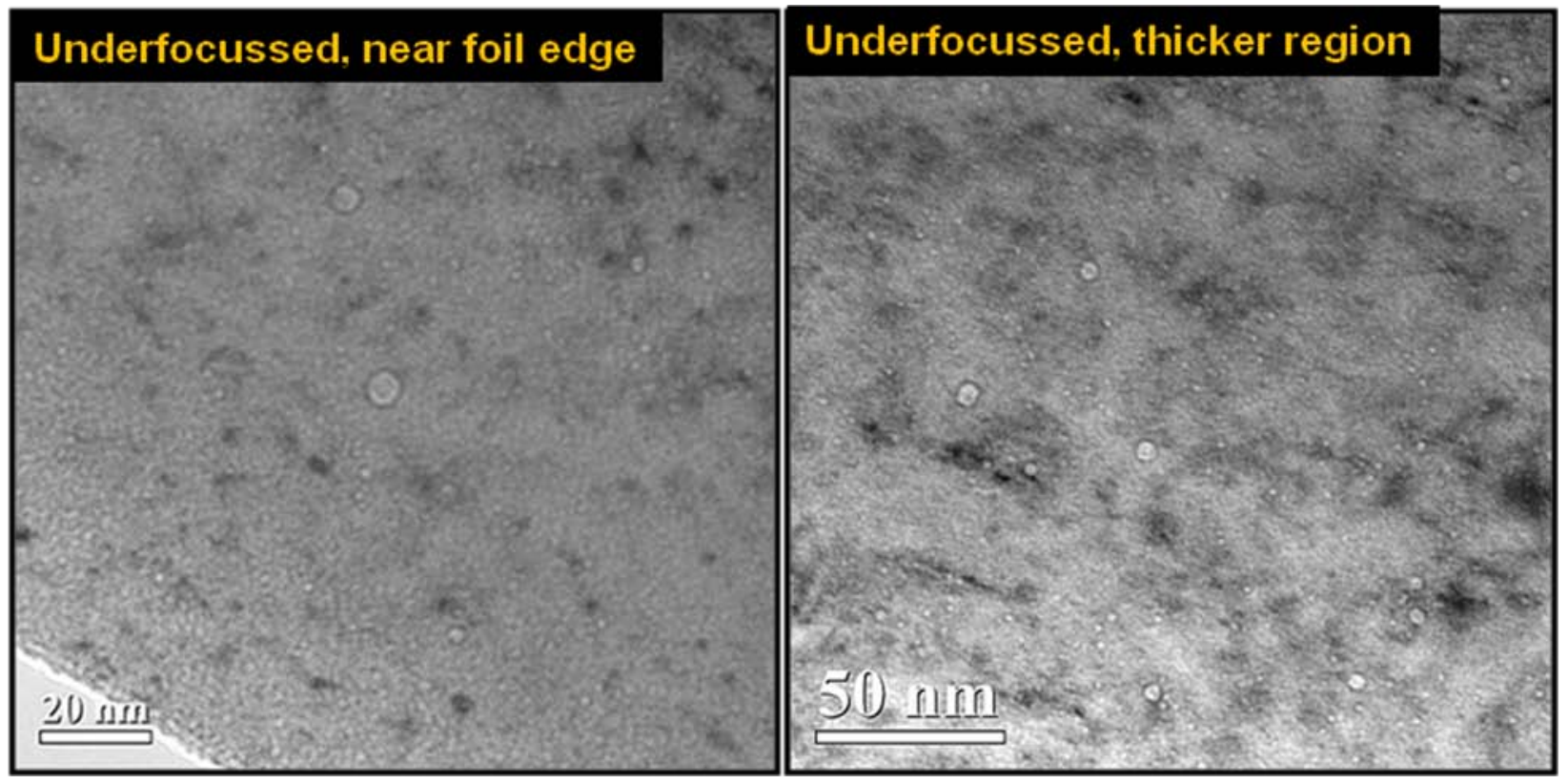

Figure 4. Small He bubbles and larger voids are visible in the AT F82H samples irradiated to 3.9 dpa at $400^{\circ} \mathrm{C}$. The bubbles are randomly distributed in the lath interiors, with much less association with lath boundaries, carbide interfaces or dislocations compared to that observed at $500^{\circ} \mathrm{C}$.

Table 2. The average diameter and number density of the cavities.

\begin{tabular}{|c|c|c|c|c|c|}
\hline & \multicolumn{3}{|c|}{ As-Tempered } & \multicolumn{2}{c|}{$\begin{array}{c}\text { As-Tempered \& } \\
20 \% \text { Cold Worked }\end{array}$} \\
\cline { 2 - 6 } & $\begin{array}{c}400^{\circ} \mathrm{C} \\
90 \mathrm{appm}\end{array}$ & $\begin{array}{c}500^{\circ} \mathrm{C} \\
190 \mathrm{appm}\end{array}$ & $\begin{array}{c}500^{\circ} \mathrm{C} \\
380 \mathrm{appm}\end{array}$ & $\begin{array}{c}500^{\circ} \mathrm{C} \\
190 \mathrm{appm}\end{array}$ & $\begin{array}{c}500^{\circ} \mathrm{C} \\
380 \mathrm{appm}\end{array}$ \\
\hline $\begin{array}{c}\text { Avg. Size with } \\
\text { Std Deviation } \\
(\mathrm{nm})\end{array}$ & $2.6 \pm 1.3$ & $2.4 \pm 1.5$ & $3.4 \pm 1.6$ & $1.4 \pm 0.3$ & $1.9 \pm 0.7$ \\
\hline $\begin{array}{c}\text { Density } \\
\left(\mathrm{m}^{-3}\right)\end{array}$ & $5.7 \times 10^{22}$ & $5.2 \times 10^{22}$ & $7.9 \times 10^{22}$ & $8.1 \times 10^{22}$ & $1.1 \times 10^{23}$ \\
\hline
\end{tabular}



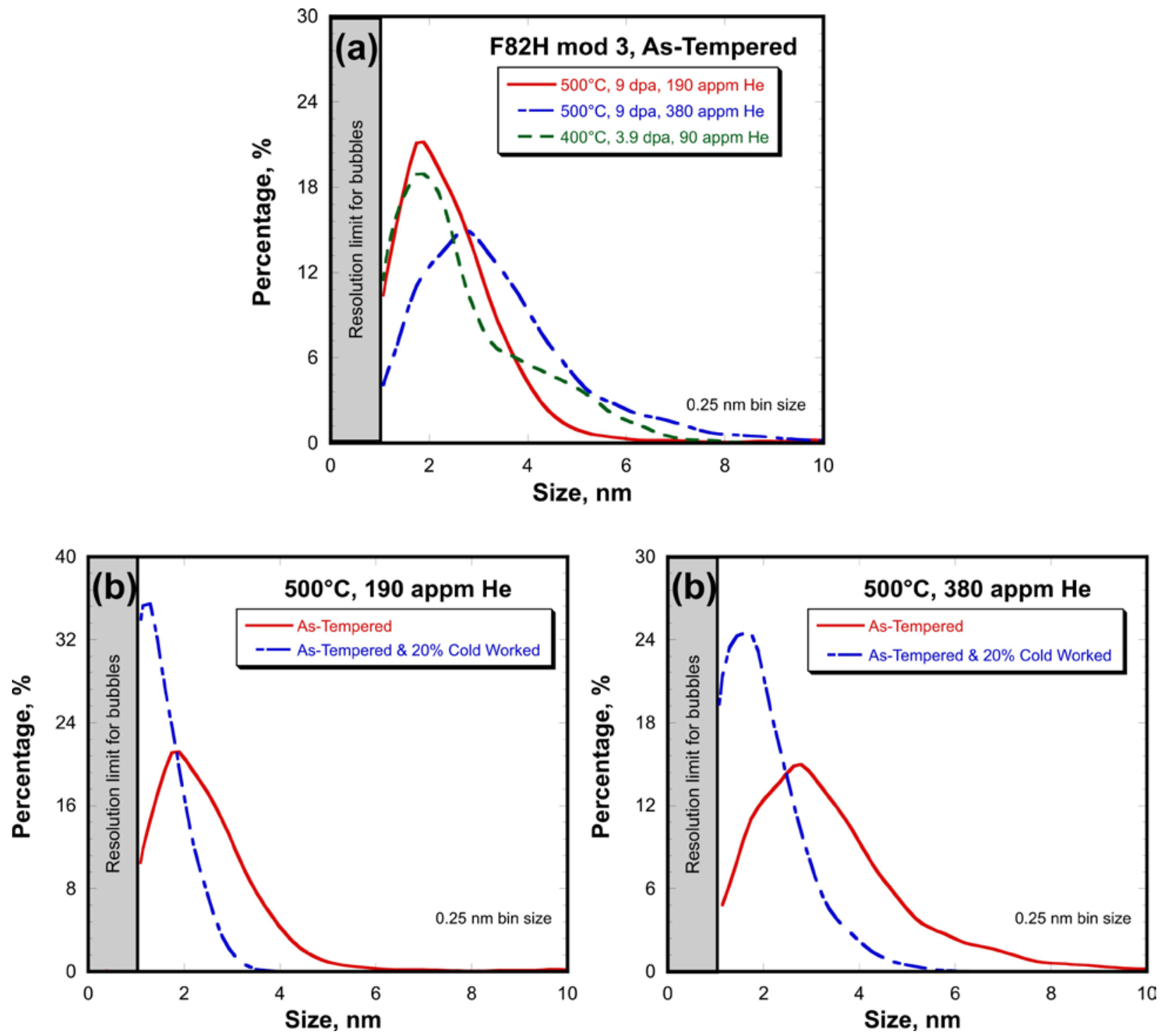

Figure 5. Size distributions are shown comparing the cavity distributions in $\mathrm{F} 82 \mathrm{H}$ mod3 alloy irradiated at (a) $400^{\circ} \mathrm{C}$ and $500^{\circ} \mathrm{C}$ and (b) irradiated at $500^{\circ} \mathrm{C}$ for two different He levels in both the AT and CW conditions. Note: The cavity size distributions and number densities are being reexamined. A practical resolution limit is about $1 \mathrm{~nm}$. While bubbles smaller than $1 \mathrm{~nm}$ can be seen, it is difficult to accurately measure their size. Furthermore, there exists the possibility of bubbles being present that are too small to separate from the artifacts in the foil. 
Examples of the dislocation structure at all three irradiation temperatures are shown in Figure 6. Preliminary characterization of the alloys irradiated at $500^{\circ} \mathrm{C}$ revealed a moderate density of line dislocations accompanied with a low density of large loops in both the AT and CW conditions. A rough estimate taken from bright field images near a $\mathbf{g}(011)$ vector indicates a dislocation density of $\approx 0.8 \times 10^{15}$ $\mathrm{m}^{-2}$ in both alloy conditions. Given the surprising result that the dislocation densities are similar between the AT condition and AT \& CW condition, these preliminary observations need further elaboration and confirmation, including determining the nature of the line dislocations. At $400^{\circ} \mathrm{C}$, relatively large dislocation loops were the dominant irradiation induced feature. In the AT condition the loops had an average size of $\approx 13 \mathrm{~nm}$ with a number density of $\approx 10^{21} \mathrm{~m}^{-3}$. In the CW condition the loop size was slightly larger at $\approx 20 \mathrm{~nm}$ with a lower density of $\approx 0.6 \times 10^{21} \mathrm{~m}^{-3}$. Again, these numbers will be refined and the nature of the loops determined in ongoing work. The dislocation structure at $300^{\circ} \mathrm{C}$ in the AT condition was composed of a uniform density of line segments. In the $\mathrm{CW}$ condition, the dislocation structure was dominated by a tangled network of line dislocations introduced by the cold working prior to irradiation. Small dislocation loops in the range of 1-5 nm could be seen, but their density has yet to be determined. Notably, the dislocation structures were qualitatively similar in the in both the He-implanted and unimplanted regions.

\section{Summary}

Irradiation at $500^{\circ} \mathrm{C}$ to $9 \mathrm{dpa}$ at $380 \mathrm{appm} \mathrm{He}$ ? led to a large population of bubbles and smaller number of voids. Most of the cavities were associated with pre-existing dislocations in both the AT and CW conditions. In the AT condition containing $380 \mathrm{appm} \mathrm{He}$, the dislocations appear to have climbed away from the stringers of voids and bubbles that formed on the dislocations at earlier stages in the irradiation. Some evidence of residual void/bubble-dislocation association was found for the $500^{\circ} \mathrm{C}$ irradiations that produced $190 \mathrm{appm} \mathrm{He}$. Cold working led to a larger number of smaller cavities and suppressed the formation of larger voids. Smaller bubbles were also observed on lath boundaries and to a lesser extent carbide interfaces in all four alloy-irradiation conditions at $500^{\circ} \mathrm{C}$.

Irradiation of the AT alloy at $400^{\circ} \mathrm{C}$ to $3.9 \mathrm{dpa}$ and $90 \mathrm{appm}$ He resulted in a similar number density and average size of cavities compared to those observed the $500^{\circ} \mathrm{C}$ irradiation that produced 190 appm He. The cavities also didn't appear to be as strongly associated with dislocations at the lower He level and temperature. Bubbles in the $\mathrm{CW}$ condition irradiated at $400^{\circ} \mathrm{C}$ could not be distinguished from possible artifacts, so measurements exist for this condition. Similarly, bubbles that could be clearly distinguished from foil artifacts were not observed in the case of the $300^{\circ} \mathrm{C}$ irradiation, in either the AT or CW conditions.

Preliminary characterization of the dislocation structure yielded a complex picture of varying densities of line dislocations, dislocation loops and line segments that vary depending on the irradiation temperature and dose as well as the AT versus CW condition. However, these preliminary observations suggest that He has little qualitative effect on dislocation structures. 


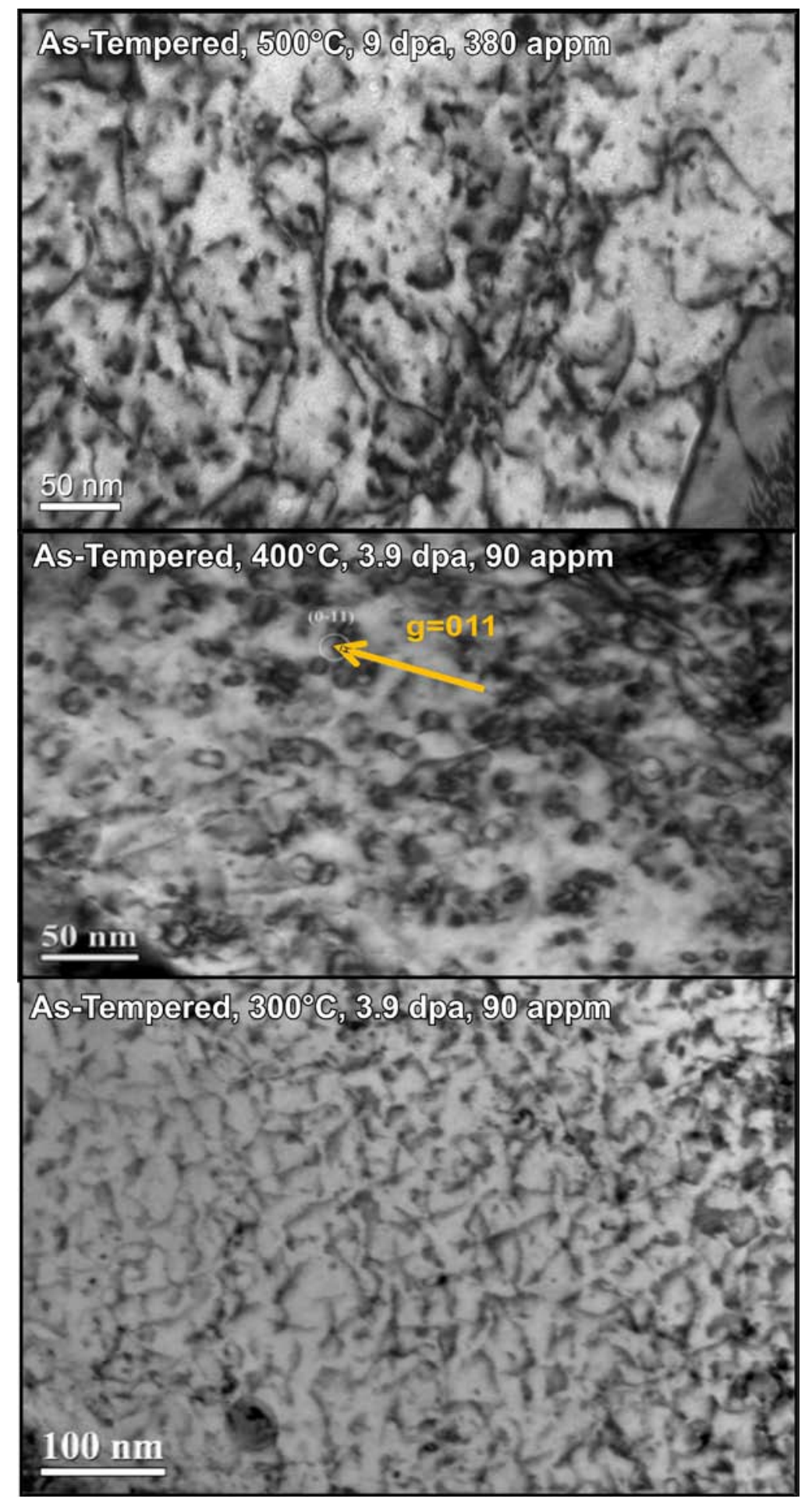

Figure 6. Dislocation structures in the AT condition after irradiation at 300,400 and $500^{\circ} \mathrm{C}$. Variations in the irradiation temperature and dose lead to significant differences in line versus dislocation loop populations. The nature of these dislocation structures will be determined in subsequent work. 


\section{References}

1. G.R. Odette, P. Miao, T. Yamamoto, D.J. Edwards, R.J. Kurtz, Fusion Materials Semiannual Report $1 / 1$ to 6/30/2008 DOE/ER313/44 (2008) p. 41.

2. T. Yamamoto, G. R. Odette, P. Miao, D. T. Hoelzer, J. Bentley, N. Hashimoto, H. Tanigawa, R. J. Kurtz, J. Nucl. Mater. 367-370 (2007) 399.

3. R.J. Kurtz, G.R. Odette, T. Yamamoto, D.S. Gelles, P. Miao, B.M. Oliver, J. Nucl. Mater. 367-370 (2007) 417.

4. $\quad$ T. Yamamoto, G.R. Odette, P. Miao, D.J. Edwards, R.J. Kurtz, J. Nucl. Mater. 386-388 (2009) 338341

5. T. Yamamoto, G. R. Odette, L. R. Greenwood, Fusion Materials Semiannual Report 1/1 to 6/30/2005 DOE/ER-313/38 (2005) 95. 